\title{
Biodiversity and Bio-Resource Capacity of Marine Environment in the Adaptive Model of the Ecological-Economic System Coast-Sea
}

\author{
I. E. Timchenko*, E. M. Igumnova \\ Marine Hydrophysical Institute, Russian Academy of Sciences, Sevastopol, Russian Federation \\ *e-mail: timchenko.syst.analysis@mhi-ras.ru
}

The adaptive model of managing consumption of marine bio-resources by the coastal economic subsystem which is a part of the ecological-economic system coast-sea is constructed. The marine part of the model is represented by the adaptive version of the plankton dynamics and nitrogen cycle model in which the chlorophyll $a$ concentration observations are assimilated. Management of the consumed bio-resources volume is based on tracing the deviations of the marine biodiversity index from its average (undisturbed) value which is represented as an estimate of the stationary value of the environment bio-resource capacity. The bio-resource capacity integral model controlling the balance between the rates of consumption and reproduction of marine bio-resources is proposed. The model equations are constructed by the method of adaptive balance of influences; at that the influence coefficients are expressed through the normalized ratios of the variables' mean values. To preserve the marine environment biodiversity, the right-hand sides of the equations contain the agents for managing the scenarios of ecological-economic processes. These agents ensure imposing fines for sea pollution caused by the coastal economic subsystem. Represented are the results of computational experiments confirming economic expediency of introducing new technologies in the coastal subsystem which, in their turn, contribute to economic efficiency of bio-resource consumption and preserve the marine environment bio-resource capacity. It is shown that the marine environment bio-resource capacity is an integral value of the biodiversity index determined for a certain time interval. Thus, in order to use rationally bio-resources of the sea coastal zone, it is necessary to control both biodiversity and bioresource capacity of the marine environment. These two indices indicating ecological state of the sea coastal zone serve the criteria for managing the integrated ecological-economic system coast-sea which are used to derive economic benefit from consumption of marine bio-resources provided that the marine environment quality is preserved.

Keywords: adaptive model, marine ecosystem, biodiversity and bio-resource capacity of marine environment, fines for pollution, management agents, scenarios of environmental and economic processes.

For citation: Timchenko, I.E. and Igumnova, E.M., 2018. Biodiversity and bio-resource capacity of marine environment in the adaptive model of the ecological-economic system coast-sea. Physical Oceanography, [e-journal] 25(3), pp. 207-219. doi: 10.22449/1573-160X-2018-3-207-219

DOI: $10.22449 / 1573-160 X-2018-3-207-219$

(C) 2018, I. E. Timchenko, E. M. Igumnova

(C) Physical Oceanography

Introduction. One of the main ecological economics concepts is a point that sustainable development of economic system of every region is supported by its ecosystem [1-6]. Ecological economics of the sea coastal zone [7-15] consumes marine resources and in this sense the coastal zone economic development depends on marine ecosystem capability for recovery of the consumed resources. The main of them are biological resources and assimilation ones, i.e. the capability of the sea to dispose industrial, agricultural and domestic wastes of social-economic system of 
coastal territory. Marine environment resources are limited and are affected by temporal changes. Therefore, the quantitative models and estimates which allow one to control their dynamics and forecast their development trends are needed.

The availability of marine bio-resources depends on the marine environment ecological state, which is traditionally estimated using the biodiversity index [5]. The most suitable for such an assessment of the marine environment state is the definition adopted in mathematical biology [16] and, in particular, in population dynamics [17]. This refers to "current capacity" term, used to assess the ability of the ecosystem to maintain the existence of a certain number of living organisms. In terms of consumption of marine bio-resources by the coastal economic system, it is advisable to introduce such estimation for the integral characteristic of marine environment bio-resource capacity.

Bio-resource capacity should be understood as a volume of bioresources available for use by the coastal economic system without affecting the marine environment ecological state. Withdrawal of some biological resources for economic purposes reduces the concentration of ecosystem biological objects, disturbs the balance of biochemical reactions of substance transformation and, as a result, decreases its biodiversity index. Marine environment bio-resource capacity is an integral value of biodiversity index determined at some time interval. It has its maximum permissible (threshold) value below which there is a risk of the ecosystem inability to restore the equilibrium concentrations of biological objects. Thus, for rational use of the sea coastal zone bio-resources, it is necessary to control both biodiversity and bioresource capacity of the marine environment. These two parameters of the sea coastal zone state serve as criteria for managing the integral ecologic-economic system coast-sea in order to obtain economic benefits from the consumption of marine bio-resources, while preserving the marine environment quality.

A similar task of managing the balance of consumption and reproduction of assimilation resources by the ecological-economic coast-sea system was considered in [18]. An adaptive model for managing the runoff of pollutants into the sea was proposed on the basis of the criteria for production profitability and assimilative capacity of the marine environment in relation to the level of pollution by production waste. In the modification of this model considered in the present study the the main attention is paid to the impact of marine bio-resource consumption on the change in bioresource capacity and marine environment biodiversity. As a scheme of cause-effect relationships between processes in the marine ecosystem, an adaptive version of the plankton dynamics and nitrogen cycle model by Fasham, Ducklow and McKelvie is used [19].

Adaptive model of bio-resource capacity and marine environment biodiversity. Adaptive properties of the model mean that the biodiversity index automatically adjusts to changing external conditions in order to preserve the material balance of biochemical reactions that form the bio-resource concentration. To construct an adaptive dynamic model of biodiversity, we use the Adaptive Balance of Causes method $[6,20]$. The peculiarity of the method consists in the use of a system of standard equations for all cause-effect relations between $u_{i}$ development processes. The system of standard equations has the following form: 


$$
\begin{gathered}
\frac{d u_{i}}{d t}=2 r_{i} u_{i}\left[C_{i}-\left(u_{i}-\sum_{j=1, j \neq i}^{n} a_{i j} u_{j}-A_{i}\right)\right]=2 r_{i} u_{i}\left\{C_{i}-\left[u_{i}-F_{u_{i}}\left(a_{i j} u_{j}, A_{i}\right)\right]\right\}, \\
u_{i}=\operatorname{IF}\left[u_{i}<0 ; 0 ; \operatorname{IF}\left(u_{i}>2 C_{u_{i}} ; 2 C_{u_{i}} ; u_{i}\right)\right],
\end{gathered}
$$

where $r_{i}$ - specific rates of the process changes; $C_{i}-$ their mean values; $a_{i j}-$ the coefficients of intra-system effects; $A_{i}$ - external controls. Each equation of this system contains negative second-order feedbacks between the processes and rates of their changes. These relations provide fast adaptation of development processes to each other and external effects. For the case when there is $m$ of positive and $n-m$ of negative impacts in the equations of system (1), $a_{i j}$ coefficients can be expressed in terms of normalized mean values of the simulated processes:

$$
\left.\frac{d u_{i}}{d t}=2 r_{i} u_{i}\left\{C_{i}-\left[u_{i}-\frac{C_{i}}{2 m} \sum_{j=1, j \neq i}^{m} C_{j}^{-1} u_{j}^{\prime}+\frac{C_{i}}{2(n-m)} \sum_{j=m+1, j \neq i}^{n-m} C_{j}^{-1} u_{j}^{\prime}-A_{i}\right)\right]\right\},
$$

where $u_{j}^{\prime}=u_{j}-C_{j}$.

We assume that the concentration of bio-resources in the marine environment is proportional to the value of $B D$ biodiversity index for which we use an equation of the form (3):

$$
\begin{gathered}
\frac{d B D}{d t}=2 r_{\mathrm{BD}} B D\left[C_{\mathrm{BD}}-\left(B D-\sum_{j=1, i \neq j}^{n} a_{\mathrm{BD} / u_{j}} u_{j}^{\prime}+a_{\mathrm{BD} / \mathrm{S}} S\right)\right], \\
B D=I F\left[B D<0 ; 0 ; \operatorname{IF}\left(B D>2 C_{\mathrm{BD}} ; 2 C_{\mathrm{BD}} ; B D\right)\right],
\end{gathered}
$$

where $u_{j}$ - the functions representing the concentrations of marine environment living organisms in the ecosystem model; $C_{\mathrm{BD}}$ - stationary (equilibrium) value of biodiversity index and $S$ - integral balance of bio-resource consumption and reproduction which is determined below. We express the coefficients of effects through the normalized relations of variable mean values $a_{i j}^{\prime} C_{\mathrm{BD}} / C_{j}$ and we will consider that in the ecosystem equilibrium state, when $u_{j}=C_{j}$, the rates of bio-resource consumption and reproduction are equal. Then the function $S=0$ and the equation (4) takes the following form:

$$
\frac{d B D}{d t}=2 r_{\mathrm{BD}} B D\left[C_{\mathrm{BD}}-\left(B D-\sum_{j=1, i \neq j}^{n} a_{i j}^{\prime} \frac{C_{\mathrm{BD}}}{C_{j}} u_{j}^{\prime}\right)\right] .
$$

As in the stationary state positive and negative effects balance each other, the sum of effects in the equation (5) vanishes and stationary value of biodiversity index, which we determine as $B D^{*}=C_{\mathrm{BD}}$, becomes its solution. This value is conveniently taken as the integral characteristic of marine environment bio-resource capacity in a stationary state. If the value of biodiversity index exceeds $B D^{*}$, then the ecosystem is stable towards the removal of a part of bio-resources and to a corresponding decrease of this index. Otherwise, the environment bio-resource capacity begins to decrease and this threatens to degrade the ecosystem.

PHYSICAL OCEANOGRAPHY VOL. 25 ISS. 3 (2018) 
$B D$ index variations occur in the vicinity of a stationary value, and they depend on living objects concentrations of the ecosystem. But living objects concentrations are determined by the factors that limit their existence. Positive factors contribute to the increase of their concentration providing their food and breathing. Negative factors are the presence of predators and marine environment pollution. Therefore, in the equation (5) the concentration of living objects should be limited using the management agents $A G\left(M_{\mathrm{BD}}, N_{\mathrm{BD}}\right)$ which consider only the minimum values of positive types of resources $M_{\mathrm{BD}}$ and only the maximum (in modulus) values of negative types of resources $N_{\mathrm{BD}}$. In general case the equation (4) for the biodiversity index should be written in the following form:

$$
\begin{gathered}
\frac{d B D}{d t}=2 r_{\mathrm{BD}} B D\left\{B D^{*}-\left[B D-A G\left(M_{\mathrm{BD}}, N_{\mathrm{BD}}\right)+a_{\mathrm{S}_{\mathrm{BD}}} S_{B D}\right]\right\}, \\
A G\left(M_{\mathrm{BD}}, N_{\mathrm{BD}}\right)=I F\left[a_{\mathrm{BD} / u_{k}}>0 ; M_{\mathrm{BD}}(t) ; 0\right]+I F\left[a_{\mathrm{BD} / u_{l}}<0 ;-N_{\mathrm{BD}}(t) ; 0\right], \\
k=1,2, \ldots, m, l=m+1, m+2, \ldots, n ; \\
M_{\mathrm{BD}}(t)=\arg \min \left[a_{\mathrm{BD}} / u_{m+1} u_{m+1}(t) ; \ldots ; a_{\mathrm{BD} / u_{n}} u_{n}(t)\right], \\
N_{\mathrm{BD}}(t)=\arg \max \left[a_{\mathrm{BD}} / \mathrm{u}_{\mathrm{m}+1} u_{m+1}(t) ; \ldots ; a_{\mathrm{BD} / \mathrm{u}_{\mathrm{n}}} u_{n}(t)\right] .
\end{gathered}
$$

Then an increase of predator concentration, (brought by currents, for example) will not affect the raise of biodiversity index, but the increase of amount of other species of animals eaten by the predators will decrease the concentrations of these animals and, therefore, reduce the value of the biodiversity index.

In order to control the dynamics of consumption and reproduction of bioresource concentration, it is reasonable to use an integral over the time period $(0, t)$ estimate of difference between $S_{\text {ext }}(t)$ biodiversity index decrease cased by the consumption of bio-resources and its reproduction by the ecosystem $S_{\text {rec }}(t)$ :

$$
S(t)=S_{\text {ext }}(t)-S_{\text {rec }}(t)=a_{S / V} \int_{0}^{t}[1-R(\tau)] V(\tau) d \tau .
$$

In this expression it is assumed that the consumption of bio-resource concentration is proportional to the volume of seafood produced by $V(\tau)$ coastal economic system. Its reproduction is managed by the function (agent) of marine environment bio-resource capacity:

$$
R(t)=I F\left\{B D>B D^{*} ; 1 ; I F\left[T X_{\text {acc }}<T X_{\text {acc }}^{*} ; \exp \left(-\alpha_{R} \tau\right) ; R(t)+[1-R(t)]\left[1-\exp \left(-\beta_{R} \tau\right)\right]\right]\right\} .
$$


The cause for $R(t)$ function use are the following assumptions. Reproduction of a part of bio-resource concentration taken from the marine environment is possible in two ways. Firstly, this occurs due to natural biochemical reactions accompanying the ecosystem pursuit to maintain its stable state. Due to this property, the rate of bio-resource concentration reproduction raise up to the one of their consumption. As a result, $S(t)$ integral balance remains equal to zero. This ecosystem state is maintained until the ecosystem biodiversity index $B D$ falls below the maximum permissible value $B D^{*}$, when the bio-resource reproduction rate begins to lag behind the one of their consumption. This lag is considered by the exponential function with $\alpha_{R}$ parameter in the expression (8).

Secondly, the management of the balance of bio-resource consumption and reproduction is possible through environmental activities. When bio-diversity index is explained by marine environment pollution with domestic and industrial wastes, the reproduction of bio-resource concentration is possible due to $T X$ penalties imposed on the coastal system. Penalties increase the cost of seafood which results in the reduction of production profitability, to the drop production output and, as a consequence, to the decrease of pollutant flux getting into the sea.

Another option to manage the volumes of consumed bio-resources is a conversion of production to resource-saving technologies. This option provides $T X_{\text {acc }}<T X_{\text {acc }}^{*}$ condition the management agent (8). It is accepted that the imposition of penalties results in the accumulation of funds $T X_{\text {acc }}$ in the fund of new technologies used for environmental protection actions. When the volume of fund reaches $T X_{\text {acc }}^{*}$ value, the marine environment pollution and bio-resource consumption by the coastal social-economic system significantly decrease and biodiversity index increases up to $B D^{*}$ value again. This process takes place with time delay which is regulated by $\beta_{\mathrm{R}}$ parameter in the expression (8).

The scheme of cause-effect relations and equations of the model of ecological-economic system coast-sea. The scheme depicted in Fig. 1 realizes the main tasks of management of marine resource consumption and reproduction processes in the model of coast-sea system. The simplified scheme of plankton dynamics and the nitrogen cycle (taken from [19]) in which the concentrations of phytoplankton $P$, zooplankton $Z$ and bacteria plankton $B$ serve as the food chain objects forming the biodiversity index in equation (5) are used as the ecological part of the model. The concentrations of nitrates $N_{\mathrm{n}}$, ammonium $N_{\mathrm{a}}$, dissolved organic matter $N_{\mathrm{d}}$ and detritus $D$ were used as the chemical elements of the ecosystem model. It was considered that this simplified model is sufficient to explain the proposed principle of bio-resource consumption management in the coast-sea system.

The processes developing in the economic part of the model are named and shown in Fig. 1. The arrows indicate the main intra-system effects.

The key role was played by the management agents which made local decisions. $A G_{\mathrm{V}}$ production management agent ensured that production cost $E$ did not exceed the market price $P$ of the products, penalty imposing agent $A G_{\mathrm{TX}}\left(P L, P L^{*}\right)$ - that the pollution concentration in the marine environment $P L$ did not exceed the maximum permissible value $P L^{*}$, biodiversity agent $A G_{\mathrm{BD}}\left(B D, B D^{*}\right)$ ensured that biodiversity index did not fall below its stationary state $B D^{*}$ and bio-resource capacity agent $R$ controlled the integral balance of bio-resource consumption and reproduction rates. As new (resource-saving) manufacturing technologies the process of the coastal runoff purification was provided. For this purpose, runoff treat- 
ment agent $A G_{\mathrm{PL}}\left(T X_{\mathrm{acc}}, T X_{\mathrm{acc}}^{*}\right)$ activated the environmental protection measures when the fund of new technologies $T X_{\text {acc }}$ reached $T X_{\text {acc }}^{*}$ value. Thus, the management of processes in the coast-sea system was based on numerous feedbacks allowing one to set and maintain the regime of rational marine bio-resource consumption.

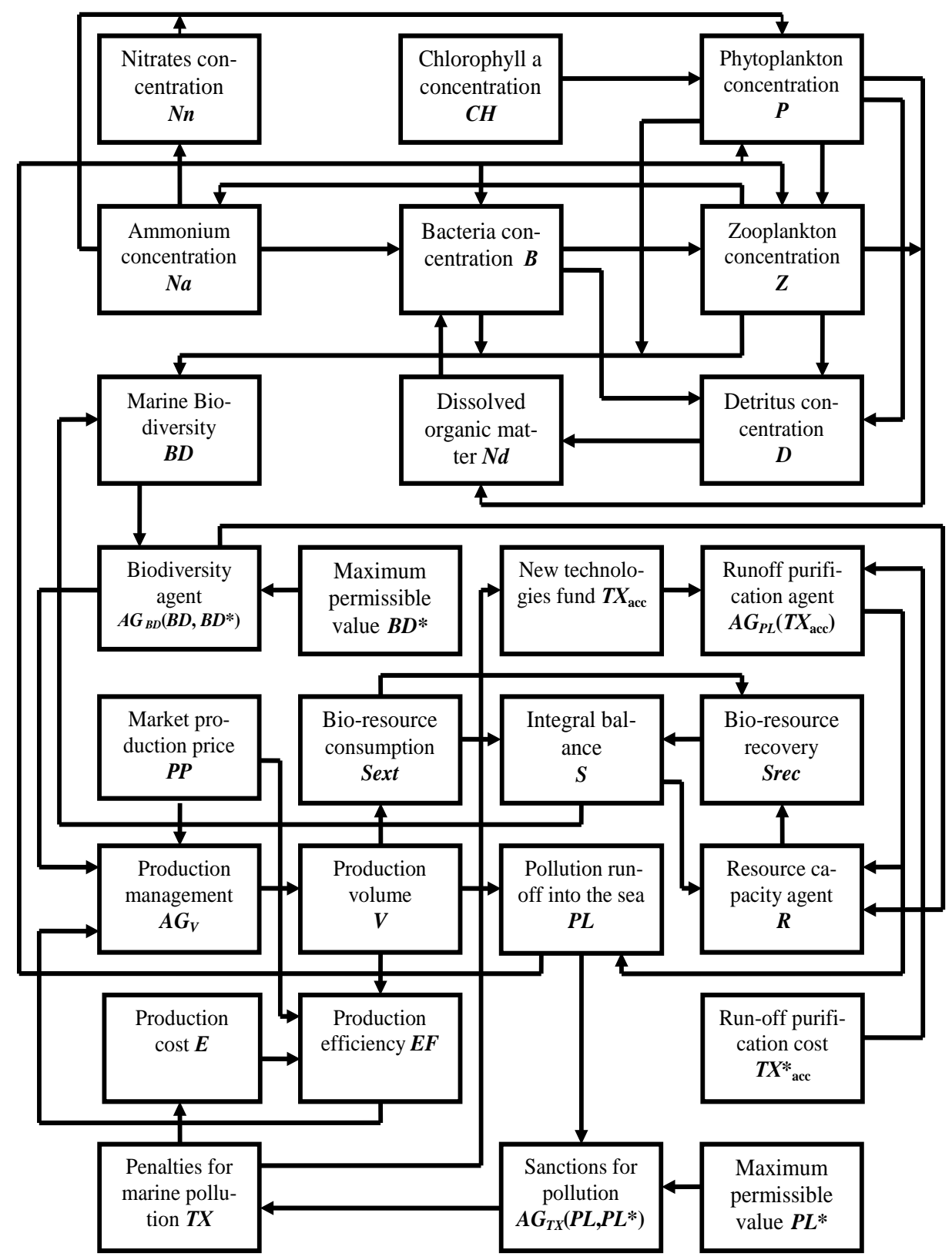

Fig. 1. Model of the ecological-economic system coast-sea 
Using the notations of cause-effect relations given in the conceptual model of the system (Fig. 1) and modular equations of the Adaptive Balance of Causes method (1)-(2), we write out the equations of the coastal economic subsystem and coastal ecosystem. Since the equations of ABC-method have the modular structure, it is sufficient to write down only the influence functionals for each equation of the model (1)-(2). Instead of $u_{i}, u_{j}$ we substitute in them the corresponding notations: DM for the demand for products (goods and services), $V$ - for the volume of products, $P L-$ for the pollution concentration in the marine environment, $T X$ - for penalties for pollution and marine environment biodiversity index reduction, $E$ - for the costs of product manufacturing. We also use the notations from [19] for the following concentrations: phytoplankton- $P$, zooplankton- $Z$, bacteria plankton- $B$, detritus- $D$, ammonium- $N_{a}$, nitrates $-N_{n}$ and dissolved organic matter $-N_{d}$.

Then we obtain:

$$
\begin{gathered}
F_{\mathrm{DM}}=a_{\mathrm{DM} / \mathrm{PP}} P P-\left(D M^{*}-C_{\mathrm{DM}}\right) ; \\
F_{\mathrm{V}}=A G_{\mathrm{V}}(P, E)+A G_{\mathrm{V}}\left(B D, B D^{*}\right)-a_{\mathrm{V} / \mathrm{D}} D, \\
A G_{\mathrm{V}}(P, E)=I F\left\{P>E ; 0 ; V_{\mathrm{E}}^{*}\left[1-\exp \left(-b_{\mathrm{V}} \tau\right)\right]\right\}, \\
A G_{\mathrm{BD}}\left(B D, B D^{*}\right)=I F\left\{B D>B D^{*} ; 0 ; V_{\mathrm{BD}}^{*}\left[1-\exp \left(-b_{\mathrm{BD}} \tau\right)\right]\right\} ; \\
F_{\mathrm{PL}}=-a_{\mathrm{PL} / \mathrm{V}} V+A G_{\mathrm{PL} / \mathrm{TX} \mathrm{acc}}\left(T X_{\mathrm{acc}}, T X_{\mathrm{acc}}^{*}\right), \\
A G_{\mathrm{PL} / \mathrm{TX} \mathrm{acc}}\left(T X_{\mathrm{acc}}, T X_{\mathrm{acc}}^{*}\right)=a_{\mathrm{PL} / \mathrm{TX} \mathrm{acc}} I F\left\{T X_{\mathrm{acc}}<T X_{\mathrm{acc}}^{*} ; 0 ; P L\left[1-\exp \left(-b_{\mathrm{PL}} \tau \int_{0}^{t} T X\right]\right\},\right. \\
F_{\mathrm{TX}}=-a_{\mathrm{TX} / \mathrm{PL}} P L-A G_{\mathrm{TX} / \mathrm{PL}}\left(P L, P L^{*}\right)-A G_{\mathrm{TX} / \mathrm{BD}}\left(B D, B D^{*}\right)+T X^{*}, \\
\left.A G_{\mathrm{TX} / \mathrm{PL}}^{*}\left(P L, P L^{*}\right)=I F\left\{P L<P L^{*} ; 0 ; a_{\mathrm{TX} / \mathrm{PL}}\left(P L-P L^{*}\right) 1-\exp \left(-b_{\mathrm{TX} / \mathrm{PL}} \tau\right)\right]\right\}, \\
A G_{\mathrm{TX} / \mathrm{BD}}\left(B D, B D^{*}\right)=I F\left\{B D<B D^{*} ; 0 ; a_{\mathrm{TX} / \mathrm{BD}}\left(B D^{*}-B D\right)\left[1-\exp \left(-b_{\mathrm{TX} / \mathrm{BD}} \tau\right)\right]\right\},
\end{gathered}
$$

where $T X^{*}$ is a component of penalties not related to environment pollution and consumption of bioresources;

$$
F_{\mathrm{E}}=-a_{\mathrm{E} / \mathrm{TX}} T X+E^{*},
$$

where $E^{*}$ is a component of product costs related to operating expenses; 


$$
F_{\mathrm{P}}=-a_{\mathrm{P} / \mathrm{N}_{\mathrm{a}}} N_{a}-a_{\mathrm{P} / \mathrm{N}_{\mathrm{a}}} N_{n}+a_{\mathrm{P} / \mathrm{Z}} \mathrm{Z}-a_{\mathrm{P} / \mathrm{CH}} C H,
$$

where through $a_{\mathrm{P} / \mathrm{CH}} \mathrm{CH}$ an external effect of chlorophyll $a$ observations is denoted. The observations are assimilated in the equation for phytoplankton and serve as an external drive from the dynamics of the marine environment for the concentrations of all the substances modeled in this ecosystem.

$$
\begin{gathered}
F_{\mathrm{Z}}=-a_{\mathrm{Z} / \mathrm{B}} B-a_{\mathrm{Z} / \mathrm{D}} D-a_{\mathrm{Z} / \mathrm{P}} P ; \\
F_{\mathrm{B}}=-a_{\mathrm{B} / \mathrm{N}_{\mathrm{a}}} N_{a}-a_{\mathrm{B} / \mathrm{N}_{\mathrm{d}}} N_{d} ; \\
F_{\mathrm{D}}=-a_{\mathrm{D} / \mathrm{P}} P-a_{\mathrm{D} / \mathrm{Z}} Z ; \\
F_{\mathrm{N}_{a}}=a_{\mathrm{N}_{\mathrm{a}} / \mathrm{P}} P+a_{\mathrm{N}_{\mathrm{a}} / \mathrm{B}} B-a_{\mathrm{N}_{\mathrm{a}} / \mathrm{Z}} Z ; \\
F_{\mathrm{N}_{\mathrm{n}}}=a_{\mathrm{N}_{\mathrm{n}} / \mathrm{P}} P ; \\
F_{\mathrm{N}_{\mathrm{d}}}=-a_{\mathrm{N}_{\mathrm{d}} / \mathrm{P}} P-a_{\mathrm{N}_{\mathrm{d}} / \mathrm{Z}} Z-a_{\mathrm{N}_{\mathrm{d}} / \mathrm{D}} D+a_{\mathrm{N}_{\mathrm{d}} / \mathrm{B}} B ; \\
F_{\mathrm{BD}}=A G\left(M_{\mathrm{BD}}\right)+a_{\mathrm{BD} / \mathrm{S}} S .
\end{gathered}
$$

The predetermined constants of the modeled processes are indicated by “*”" sign in the expressions (9)-(10). Economic profitability of manufacturing was calculated by the logarithm of the relation of economic system $I_{\text {acc }}(t)$ incomes to expenses $E_{\text {acc }}(t)$ accumulated over $(0, t)$ time period:

$$
I_{\text {acc }}=\int_{0}^{t} P^{*} V(t) d t, \quad E_{\text {acc }}=\int_{0}^{t} E(t) V(t) d t, \quad E F=\ln \frac{1+I_{\text {acc }}}{1+E_{\text {acc }}} .
$$

The results of computational experiments on managing the processes of marine environment bio-resource consumption and reproduction. We will assume that a priori there is minimal information about the ecological and economic system: only the mean values of its variables $C_{i}$, the presence of intra-system effects and their signs are known. To determine $a_{\mathrm{M} / \mathrm{N}}$ effect coefficients we use the formulas from the equations (3) in which we substitute the known mean values $C_{i}$ and deviations from them of the corresponding variables. We write down the model (3), (9)-(11) in finite differences using the assumption that links computational time step with the specific rate of function change. For the simplicity, we will assume this rate to be equal to zero: $2 \Delta t r_{i} C_{i}=1$. Then the model equations in finite differences will take the following general form:

$$
\begin{gathered}
u_{i}^{k+1}=2 u_{i}^{k}\left\{1-\frac{1}{2 C_{i}}\left[u_{i}^{k}-F_{u_{i}}\left(u_{j}^{k}, A_{i}^{k}\right)\right]\right\} ; \\
u_{i}^{k}=I F\left[u_{i}^{k}<0 ; 0 ; \operatorname{IF}\left(u_{i}^{k}>2 C_{i} ; 2 C_{i} ; u_{i}^{k}\right)\right] .
\end{gathered}
$$


As experience of applying such equations $[6,8,18,20]$ has shown, iterative algorithms for their solution quickly converge to stable values even when using the simplest Euler scheme [21].

For testing the proposed scheme for managing the model of the ecologicaleconomic system, the scenarios of development processes at different values of the model parameters were constructed. As the mean values of the ecosystem variables, the numbers of the same order from $0.5-1.5 \mathrm{mg} / \mathrm{m}^{3}$ range were specified. This is not important from the point of view of the modeling purpose, but makes it convenient to compare scenarios of different processes among themselves. For the same purpose, a general scale of variability $(0,10)$ for dimensionless units was chosen for the scenarios of economic processes. The calculations were carried out in 365 dimensionless time steps.
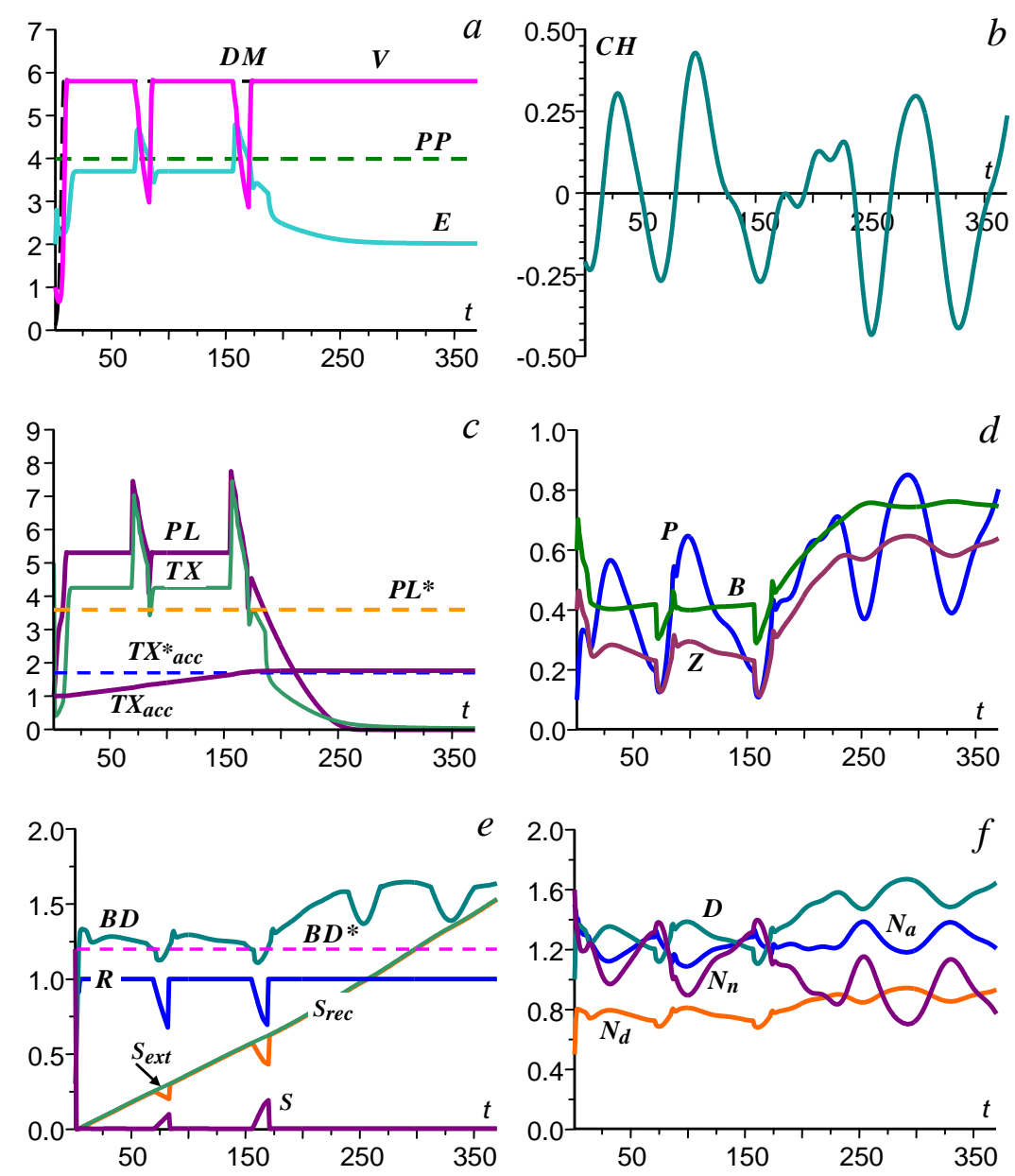

Fig. 2. Scenarios of the ecological-economic processes in the coast-sea system obtained in the first experiment 
Fig. 2 and 3 show the results of two experiments carried out under the assumption that the coastal economic subsystem tries to satisfy the constant demand $D M$ on the seafood production polluting the marine environment with its production wastes. Their concentration $P L$ is proportional to production volume $V$. Conditions of the development of processes in these experiments were determined by the coefficients of effects and model parameters (9)-(12). Both characteristics were similar except for insignificant differences in mean values of processes and values of stationary marine environment bio-resource capacity $B D^{*}$.
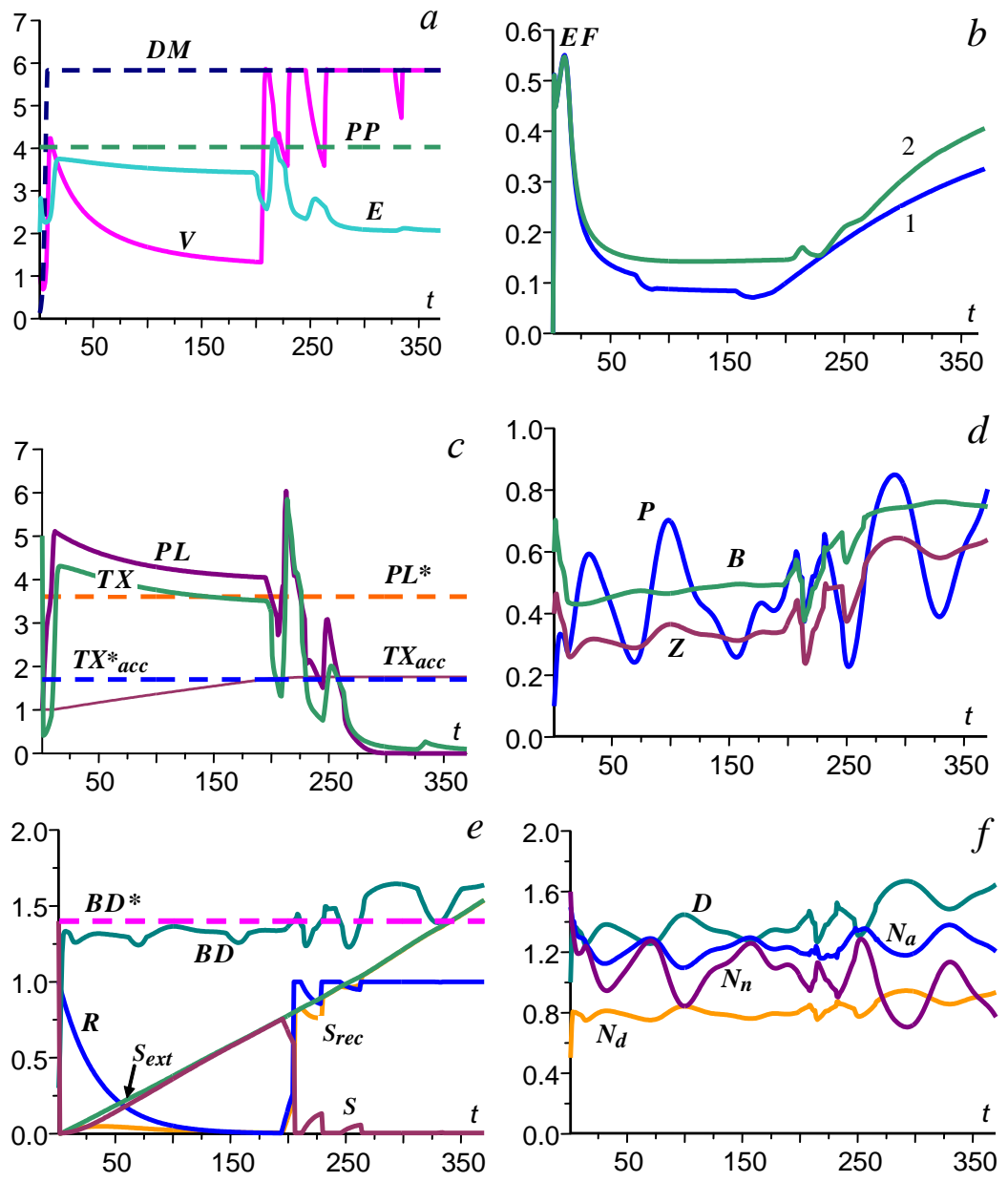

Fig. 3. Scenarios of the ecological-economic processes in the coast-sea system obtained in the second experiment

We consider the procedure for managing the system using the example of the first experiment scenarios shown in Fig. 2. In that experiment bio-resource capacity parameter $B D^{*}$ was $1.2 \mathrm{mg} / \mathrm{m}^{3}$. The scenarios of processes in the ecosystem were formed under external effect of chlorophyll $a$ concentration values assimilated in the model and depicted in Fig. 2, $b$. At the beginning of the experiment, the biodiversity index $B D$ was higher than its average value (Fig. 2, $e$ ), but the concentra- 
tion of pollutants in the sea was significantly higher than the maximum permissible value $P L^{*}=3.6$ (Fig. $2, c$ ). This led to the rapid growth of penalties for pollution (Fig. 2, $c$ ) and an increase in manufacturing costs $E$. However, until the $70^{\text {th }}$ time step production remained profitable because the product cost did not exceed the seafood cost $(E<P P)$. Therefore, the product output and biodiversity index decrease continued. From $70^{\text {th }}$ to $86^{\text {th }}$ and then from $155^{\text {th }}$ to $183^{\text {th }}$ step of computations the biodiversity index decreased below its mean value $B D^{*}$ (Fig. 2,e). The reason for this was a decrease in the concentrations of phytoplankton and zooplankton (Figure 2, d), caused by two successive minima of chlorophyll a concentration (Fig. 2, b) occurring at these intervals. The reason for this was a decrease in the concentrations of phytoplankton $P$ and zooplankton $Z$ (Fig. 2, $d$ ) caused by two successive minima of chlorophyll $a$ concentration (Fig. 2, $b$ ) occurring at these intervals. As in the equation (6) $A G\left(M_{\mathrm{BD}}\right)$ management agent monitored the minimum values of functions forming the biodiversity index, its scenario in these time intervals depended on zooplankton concentration (Fig. 2, $d$ ). Therefore, the graph of the scenario fell below the permissible value $B D^{*}$. Consumption of bio-resources should have been limited, and $A G_{\mathrm{TX} / \mathrm{PL}}\left(P L, P L^{*}\right)$ management agent sharply increased the penalties (Fig. 2, c). Simultaneously, the agents $A G_{\mathrm{V}}(P, E)$ and $A G_{\mathrm{V}}\left(B D, B D^{*}\right)$ (which manage the product output) sharply reduced bioresource consumption (Fig. 2, $a$ ).

Significant changes in the scenarios began in the $170^{\text {th }}$ step of the experiment when the fund of adoption of resource-saving technologies $T X_{\text {acc }}$ increased up to $T X_{\text {acc }}^{*}=1.7$ value and $A G_{\mathrm{PL} / \mathrm{TX}_{\text {acc }}}\left(T X_{\text {acc }}, T X_{\text {acc }}^{*}\right)$ agent in the equation for pollution concentration $P L$ activated the technology for sewage water treatment (Fig. 2, $d$ ). From this time point the decline in the pollution concentration and the concentration of biological objects started to show an upward trend (Fig. 2, $d$ ). As a result, the biodiversity index of the ecosystem also began to grow (Fig. 2, $e$ ) despite periodic decreases in chlorophyll $a$ concentration (Fig. 2, $b$ ).

Thus, due to local decisions of the coast-sea system management agents, the rates of bio-resource consumption and reproduction characterized by integral values of $S_{\text {ext }}$ and $S_{\text {rec }}$ functions were equal almost all over the entire experiment (Fig. 2,e). Marine environment resource capacity limited the use of bio-resources only in those periods when integral parameter $S$ differed from zero and the scenario of resource capacity agent $R$ dropped below one (Fig. 2, $e$ ).

The second experiment was carried out for the case when bio-resource capacity parameter $B D^{*}$ was equal to $1.4 \mathrm{mg} / \mathrm{m}^{3}$ and biodiversity index at the beginning of the experiment was lower than its mean value (Fig. 3, a). Response of management agents to the changes of the process scenarios caused by fluctuations of chlorophyll $a$ concentrations (Fig. 2, $b$ ) and the sequence of making local decisions were the same as in the first experiment. The scenarios of the resource capacity agent $R$ and the integral balance of bio-resource consumption and reproduction appeared to be significantly different (Fig. 3, e). Already at the beginning of the experiment, the integral balance $S$ grew with the increase in the volume of consumed bio-resources, as the 
function $R$ exponentially tended to zero. In these conditions, the product output management agent was forced to reduce manufacturing, although it remained profitable (Fig. 3, a). The condition for manufacturing transferring to resource-saving technologies was achieved at the $200^{\text {th }}$ step of the experiment (Figure 3, a), after which the concentration of marine environment pollution began to decrease sharply (Fig. 3, c) and scenarios of concentrations of the ecosystem biological objects got the upward trends (Fig. 3, $d$ ). As a result, biodiversity index began to rise above its mean value (with some fluctuations) (Fig. 3,e) and product output began to increase up to the demand level (Fig. 3, $a$ ).

A comparison of the results of two experiments showed a significant dependence of bio-resource capacity dynamics on the marine environment pollution level and on the bio-resource concentration reproduction rate. Bio-resource consumption management provided higher profitability in the second experiment as the bioresource consumption decrease in the first part of the experiment caused a reduction in marine environment pollution, penalties and manufacturing cost (Fig. 3, b).

Conclusion. Computational experiments with the adaptive model of the ecological-economic system coast-sea have confirmed the correctness of the chosen scheme for managing the processes of marine bio-resource consumption based on control over the marine environment biodiversity level. The proposed concept of marine environment bio-resource concept integrally considers the dynamics of biodiversity index. It provides an effective use of logic management agents which limit the manufacturing profitability and, consequently, limit the volumes of bioresource consumption in those cases when the rate of their removal from the marine environment exceeds the one of their reproduction.

\section{REFERENCES}

1. Daly, H. and Farley, J., 2010. Ecological Economics: Principles and Applications. Washington, DC: Island Press, $544 \mathrm{p}$.

2. Voinov, A., 2008. Systems Science and Modeling for Ecological Economics. New York: Academic Press, 430 p.

3. Shogren, J.F., Parkhurst, G.M. and Settle, C., 2003. Integrating Economics and Ecology to Protect Nature on Private Lands: Models, Methods, and Mindsets. Environ. Sci. Policy, [ejournal] 6(3), pp. 233-242. https://doi.org/10.1016/S1462-9011(03)00041-8

4. Crépin, A.-S., Norberg, J. and Mäler, K.-G., 2011. Coupled Economic-Ecological Systems with Slow and Fast Dynamics - Modelling and Analysis Method. Ecological Economics, [ejournal] 70(8), pp. 1448-1458. https://doi.org/10.1016/j.ecolecon.2011.02.004

5. Pearce, D. and Moran, D., 1994. The Economic Value of Biodiversity. London: Earthscan Publication Ltd., 172 p. Available at: https://www.cbd.int/financial/values/g-economicvalueiucn.pdf [Accessed 30.04.2018].

6. Timchenko, I.E., Igumnova, E.M. and Timchenko, I.I., 2016. Adaptive Balance Models for Environmental-Economic Systems. Create Space Independent Publishing Platform, 486 p.

7. Izrael, Y.A., Tsiban, A.V., Ventzel, M.V. and Shigaev, V.V., 1988. Scientific Basis for Ecological Standartization of the Man-Made Effect on Marine Ecosystem are Taken for the Baltic Sea. Oceanology, 28(2), pp. 293-299 (in Russian).

8. Ivanov, V.A., Igumnova, E.M. and Timchenko, I.E., 2012. Coastal Zone Resources Management. Kiev: Academperiodika, 304 p.

9. Ofiara, D.D. and Seneca, J.J., 2001. Economic Losses from Marine Pollution: A handbook for Assessment. Washington, DC: Island Press, 320 p. 
10. Costanza, R., Voinov, A., Boumans, R., Maxwell, T., Villa, F., Wainger, L. and Voinov, H., 2002. Integrated Ecological Economic Modeling of the Patuxent River Watershed, Maryland. Ecological Monographs, [e-journal] 72(2), pp. 203-231. https://doi.org/10.1890/00129615(2002)072[0203:IEEMOT]2.0.CO;2

11. Samhouri, J.F. and Levin, P.S., 2012. Linking Land- and Sea-Based Activities to Risk in Coastal Ecosystems. Biological Conservation, [e-journal] 145(1), pp. 118-129. https://doi.org/10.1016/j.biocon.2011.10.021

12. Halpern, B.S., Walbridge, S., Selkoe, K.A., Kappel, C.V., Micheli, F., D'Agrosa, C., Bruno, J. F., Casey, K.S. and Ebert, C. [et al.], 2008. A Global Map of Human Impact on Marine Ecosystems. Science, [e-journal] 319(5865), pp. 948-952. doi:10.1126/science.1149345

13. Elofsson, K., Folmer, H. and Gren, I.-M., 2003. Management of Eutrophicated Coastal Ecosystems: A Synopsis of the Literature with Emphasis on Theory and Methodology. Ecological Economics, [e-journal] 47(1), pp. 1-11. doi:10.1016/j.ecolecon.2003.09.001

14. McCay, B.J. and Jones, P.J.S., 2011. Marine Protected Areas and the Governance of Marine Ecosystems and Fisheries. Conserv. Biol., [e-journal] 25(6), pp. 1130-1133. https://doi.org/10.1111/j.1523-1739.2011.01771.x

15. Incorporating ecosystem services in marine planning: The role of valuation / T. Börger [et al.] // Mar. Policy. 2014. Vol. 46. P. 161-170. https://doi.org/10.1016/j.marpol.2014.01.019

16. Murray, J.D., 2008. Mathematical Biology II: Spatial Models and Biomedical Applications. N.-Y.: Springer, 736 p.

17. Sharov, A.A., 1992. The Life-System Approach: a System Paradigm in Population Ecology. Oikos. [e-journal] 63(3), pp. 485-494. doi:10.2307/3544976

18. Timchenko, I.E., Ivashchenko, I.K. and Igumnova, E.M., 2017. Management of EcologicalEconomic Processes of Pollution Accumulation and Assimilation in the Coastal Zone Marine Environment. Physical Oceanography, [e-journal] (1), pp. 68-83. doi:10.22449/1573-160X2017-1-68-83

19. Fasham, M.J.R., Ducklow, H.W. and McKelvie, S.M., 1990. A Nitrogen-Based Model of Plankton Dynamics in the Oceanic Mixed Layer. J. Mar. Res., [e-journal] 48(3), pp. 591-639. https://doi.org/10.1357/002224090784984678

20. Timchenko, I.E., Igumnova, E.M. and Timchenko, I.I., 2000. Sistemnyy Menedzhment i ABCTekhnologii Ustoychivogo Razvitiya [System Management and ABC-Technologies of Sustainable Development]. Sevastopol: ECOSI-Gidrofizika, 225 p. (in Russian).

21. Samarskiy, A.A. and Gulin, A.V., 1989. Chislennye Metody [Numerical methods]. Moscow: Nauka, 432 p.

About the authors:

Igor E. Timchenko - Head of System Analysis Department, FSBSI MHI (2, Kapitanskaya Str., Sevastopol, 299011, Russian Federation), Dr. Sci. (Phys.-Math.), Professor, Researcher ID: A-86502017, timchenko.syst.analysis@mhi-ras.ru

Ekaterina M. Igumnova - Leading Engineer, Marine Optics and Biophysics Department, FSBSI MHI (2, Kapitanskaya Str., Sevastopol, 299011, Russian Federation)

Contribution of co-authors:

Igor E. Timchenko - statement of the problem, formula algorithm of biodiversity and bioresource capacity adaptive model

Ekaterina M. Igumnova - construction of conceptual model of the coast-sea system, carrying out the numerical experiments 